Check for updates

Cite this: RSC Adv., 2019, 9, 39631

Received 22nd October 2019

Accepted 25th November 2019

DOI: 10.1039/c9ra08635h

rsc.li/rsc-advances

\section{Poly(styrene-ran-cinnamic acid) (SCA), an approach to modified polystyrene with enhanced impact toughness, heat resistance and melt strength}

\author{
Jie Wang, Zixin Yu, Peihua Li, Dachuan Ding, Xuan Zheng, Chuanqun Hu, Tao Hu, \\ Xinghou Gong, Ying Chang (D) and Chonggang Wu (D) *
}

\begin{abstract}
A poly(styrene-ran-cinnamic acid) (SCA) containing 6.8 mol\% of CA, with a $\bar{M}_{w}(\sim 217000)$ comparable to commercial polystyrene (PS), was successfully synthesised via emulsion free-radical copolymerisation as evidenced by 1744 and $1703 \mathrm{~cm}^{-1}$ infrared peak occurrences, respectively characteristic of free and dimeric carboxyl $\mathrm{C}=\mathrm{O}$ stretches. Upon the interchain hydrogen bond cross-linking by $\mathrm{CA}$, the impact toughness of the SCA was considerably improved by $47.2 \%$ against PS, the glass transition, heat deflection and Vicat softening temperatures were significantly enhanced until 117.0, 108.0 and $118.3^{\circ} \mathrm{C}$, respectively, compared with PS $\left(95.2,87.6\right.$ and $\left.96.0^{\circ} \mathrm{C}\right)$, while the extensional viscosities were near one order-of-magnitude higher than PS by which the temperature window required for appropriate meltstrengths would be greatly broadened. Meanwhile, the SCA displayed other properties basically analogous to PS. This work presents a modified PS, SCA, with enhanced toughness, heat resistance and melt strength that potentially extend its styrofoam and commodity applications.
\end{abstract}

\section{Introduction}

Since its commercialisation, polystyrene (PS), a commodity resin second in consumption only to polyethylene and poly(vinyl chloride) (PVC), has widely been used in packaging materials, automotive interiors, electronic components, etc. because of its good transparency, high modulus, superior electrical insulation, satisfactory dyeability, low price and excellent processability. Nevertheless, owing to the presence of bulky, rigid pendant phenyl groups as well as weak, nonpolar chain-segmental interactions, PS exhibits poor (impact) toughness, i.e. high brittleness; PS does not have high enough heat resistance as well to extend itself to engineering applications, and more importantly, the low melt-strength of PS limits its foamability during styrofoam production. To overcome these disadvantages especially high brittleness, researchers have made a number of modifications to improve the toughness or heat resistance of PS. Some melt-blended elastomers, e.g. natural rubber, ${ }^{1}$ butadiene rubber (BR), ${ }^{2,3}$ ethylene-propylene(diene monomer) rubber, ${ }^{4}$ etc., into PS matrices to enhance the toughness at the sacrifice of the heat resistance of PS, among which the BR-modified PS constituted commercialised highimpact polystyrene (HIPS); meanwhile, rigid polymers, e.g. poly(2,6-dimethyl-1,4-phenylene oxide), ${ }^{5}$ are blended with PS to

Hubei Provincial Key Laboratory of Green Materials for Light Industry, Collaborative Innovation Centre of Green Light-weight Materials and Processing, School of Materials and Chemical Engineering, Hubei University of Technology, Wuhan, Hubei 430068, P. R. China.E-mail: cgwu@mail.hbut.edu.cn enhance its heat resistance as well as mechanical strength, however, with its toughness reduced. Ceramic fillers, e.g. nano$\mathrm{CaCO}_{3}{ }^{6}{ }^{6}$ nano- $\mathrm{Ca}_{3}\left(\mathrm{PO}_{4}\right)_{2},{ }^{7}$ functionalised graphene oxide, ${ }^{8}$ $\mathrm{SiO}_{2},{ }^{9}$ expanded graphite, ${ }^{10} \mathrm{TiO}_{2},{ }^{11}$ etc., also fill PS to raise its heat resistance and/or mechanical strength, while its toughness is not elevated; even worse, most of the fillers cause serious wear and tear upon processing equipment such as screw extruders. (Covalent) cross-linking modification ${ }^{12,13}$ is used as well to increase the heat resistance and mechanical strength of PS, which, nevertheless, is only applicable to PS products instead of resins. Others modified PS by copolymerisation to increase its heat resistance and/or mechanical strength (e.g. commercial styrene-maleic anhydride (SMA) ${ }^{14-16}$ and styrene-acrylonitrile (SAN) ${ }^{17,18}$ styrene- $N$-phenyl maleimide, ${ }^{19}$ etc.) or to enhance its toughness (e.g. styrene-methyl methacrylate (SMMA), ${ }^{\mathbf{1 , 2 0 - 2 2}}$ acrylonitrile-butadiene-styrene (ABS), ${ }^{23,24}$ etc.), whereas nearly all of the comonomers reported in the literature are hazardous or harmful to the environment. Obviously, although people's PS-modification endeavours have given rise to commercial styrenics like HIPS, SMA, SAN, SMMA and ABS, few modifications improve both the toughness and heat resistance of PS.

Herein, an innovative modification of PS is made by copolymerising styrene with a fully green monomer, cinnamic acid (CA), recommended as a "generally recognised as safe" (GRAS) compound by the U.S. Food and Drug Administration, ${ }^{25}$ for improving both its toughness and heat resistance, as well as melt strength, by the introduction of reversible hydrogen bond cross-links. ${ }^{26}$ First, the molecular weight $\left(\bar{M}_{\mathrm{w}}\right)$ of the product, supposedly a poly(styrene-ran-cinnamic acid) (SCA), is tailored 
to a commercial grade of $200-250 \mathrm{k}$ by adjustment of the process conditions of the emulsion free-radical copolymerisation. Then, the chemical structure and CA content, respectively, of the SCA are verified by infrared spectroscopy and acid-base titration. Subsequently, as a styrenic, the SCA is systematically characterised in terms of its mechanical, thermal, processing, dielectric, fire and other physical properties, in which an emphasis is placed on the examination of its toughness, heat resistance and melt strength.

\section{Experimental}

\section{Materials}

Styrene $(\geq 98.0 \%), \quad \mathrm{NaOH} \quad(\geq 96.0 \%)$, ethanol, anhydrous $(\geq 99.7 \%), \mathrm{Al}_{2}\left(\mathrm{SO}_{4}\right)_{3} \cdot 18 \mathrm{H}_{2} \mathrm{O}(\geq 99.0 \%)$, toluene ( $\left.\geq 99.5 \%\right), \mathrm{KOH}$ $(\geq 85.0 \%)$, all of analytical reagent, and phenolphthalein (indicator grade) were purchased from Sinopharm (Shanghai) Chemical Reagents Co., Ltd., China. $\mathrm{Na}_{2} \mathrm{SO}_{4}$, anhydrous $(\geq 99.0 \%)$ and sodium dodecylsulfate (SDS), both of analytical purity, were supplied by Tianjin City Fuchen Chemical Reagents Plant, China. Potassium persulfate $\left(\mathrm{K}_{2} \mathrm{~S}_{2} \mathrm{O}_{8}\right)$ (analytical purity, $\geq 99.5 \%$ ) was obtained from Younaide Initiators (Shanghai) Co., Ltd., China. (Trans-)CA (analytical reagent, 99.0\%) was provided by Shanghai Macklin Biochemical Co., Ltd., China. A PS resin (injection grade, GPPS 123P) was received from Shanghai Secco Petrochemical Co., Ltd., China. Tetrahydrofuran (THF) (standard for $\mathrm{GC},>99.9 \%$ ) and $\mathrm{KBr}$ (spectral reagent, 99.0\%) were offered by Aladdin Industrial Corp., China. Potassium biphthalate (working chemical, $\geq 99.9 \%$ ) was afforded by Tianjin City Chemical Reagents Institute Co., Ltd., China. Deionised water was home made in our laboratory using an ultra aqua pura machine (Ulupure, China, UPT-I-10T).

Prior to its use, styrene was purified by extractions with a $5 \mathrm{wt} \%$ of $\mathrm{NaOH}$ aqueous solution to remove polymerisation inhibitor(s) and impurities and then with deionised water to eliminate the residual $\mathrm{NaOH}$, followed by drying with anhydrous $\mathrm{Na}_{2} \mathrm{SO}_{4} \cdot \mathrm{K}_{2} \mathrm{~S}_{2} \mathrm{O}_{8}$ was also refined by recrystallisation in a $0{ }^{\circ} \mathrm{C}$ ice-water bath from $50{ }^{\circ} \mathrm{C}$ deionised water, followed by filtration, washing with ice water and then with anhydrous ethanol repeatedly, air-drying in a fume hood overnight and finally vacuum drying at $50{ }^{\circ} \mathrm{C}$ for at least $12 \mathrm{~h}$. All the other chemicals were used as received without any further purification unless otherwise specified below.

\section{Emulsion free-radical copolymerisation of styrene and cinnamic acid}

Styrene was copolymerised with a small amount (10 wt $\%$ ) of CA using an emulsion method. An overhead stirrer as well as a laboratory condenser was fitted to a $2000 \mathrm{~mL}$ three-necked round-bottom flask clamped and immersed in a $50{ }^{\circ} \mathrm{C}$ water bath, into which deionised water $(600 \mathrm{~mL})$ and SDS emulsifier $(\sim 0.8080 \mathrm{~g})$ were added. Upon $250 \mathrm{rpm}$ stirred emulsification of the mixture for $0.5 \mathrm{~h}$, the (purified) styrene monomer $(60 \mathrm{~mL})$ and CA comonomer $(20.20 \mathrm{~g})$ were added to the flask, after which the water-bath temperature was increased to $75{ }^{\circ} \mathrm{C}$; meantime, the (refined) $\mathrm{K}_{2} \mathrm{~S}_{2} \mathrm{O}_{8}$ (3.2320 g) was dissolved in deionised water $(75 \mathrm{~mL})$ in a $100 \mathrm{~mL}$ beaker to prepare an initiator solution. While the bath temperature was stabilised at $75{ }^{\circ} \mathrm{C}$, the initiator solution $(25 \mathrm{~mL})$ was poured into the stirred reaction system. Once the reaction mixture appeared bluish or little liquid was observed to reflux, the bath temperature further was increased to $80{ }^{\circ} \mathrm{C}$, when the styrene $(70 \mathrm{~mL})$ and initiator solution $(25 \mathrm{~mL})$ were sequentially decanted into the system. On their constant-temperature reaction for $1 \mathrm{~h}$, the remaining styrene $(70 \mathrm{~mL})$ and initiator solution $(25 \mathrm{~mL})$ were successively dumped in, which were then reacted, again, at $80^{\circ} \mathrm{C}$ for $1 \mathrm{~h}$. At this juncture, the system was allowed to react for another $0.5 \mathrm{~h}$ at an enhanced temperature of $85^{\circ} \mathrm{C}$, contingent upon whether there was noticeably refluxed liquid (i.e. styrene) observed. After the copolymerisation reaction was completed, the emulsion was transferred to a $1000 \mathrm{~mL}$ beaker and cooled to room temperature (RT), into which $\mathrm{Al}_{2}\left(\mathrm{SO}_{4}\right)_{3}$ demulsifier $(\sim 1.6 \mathrm{~g})$ was then poured to break the emulsion under vigorous stirring. The obtained white product was Büchner filtrated, then transferred to a $1000 \mathrm{~mL}$ beaker and subsequently soaked in hot $\left(70-80{ }^{\circ} \mathrm{C}\right)$ deionised water (200-300 $\mathrm{mL}$ ) for 5 min under stirring; such a process was repeated at least 3 times. Afterwards, a similar process was repeated at least 3 times with RT anhydrous ethanol as the soaking solvent. Finally, the product was Büchner filtrated, then air-dried in a fume hood for at least 3 days and subsequently vacuum dried at $90{ }^{\circ} \mathrm{C}$ for at least 1 day to supposedly obtain an SCA resin.

\section{Characterisations of the SCA}

Gel permeation chromatography (GPC). To ascertain if it had a comparable $\bar{M}_{\mathrm{w}}$ of $200-250 \mathrm{k}$ to the (commercial) PS resin, the (potential SCA) product resin was measured at $35^{\circ} \mathrm{C}$ against the PS using a gel permeation chromatograph (Waters, Waters 1525). For the runs, THF was used as the eluent at a constant flow rate of $1.0 \mathrm{~mL} \mathrm{~min}^{-1}$ and monodisperse molecular weights (up to 1200k) of PS resins as the standards.

Fourier transform infrared (FTIR) spectroscopy. To verify success in the SCA synthesis, the FTIR spectrum of the product resin was analysed against that of the PS in a mid-IR range of 4000-500 $\mathrm{cm}^{-1}$. An FTIR spectrometer (Bruker, Tensor II) was employed to collect the absorption spectra of a $4 \mathrm{~cm}^{-1}$ resolution at RT based on 24 scans in the transmission mode. The samples were prepared as $\mathrm{KBr}$ pellets by grinding together, using a pestle and mortar, either of the two polymer powders $(\sim 2.0 \mathrm{mg})$ and the $\mathrm{KBr}(\sim 50 \mathrm{mg})$ dried with an infrared baking lamp, followed by RT compression of the mixture powder on a hydraulic press. Prior to the samples preparation, both the product resin and PS were purified by reprecipitation from toluene into a large amount of anhydrous ethanol, followed by Büchner filtration, washing with anhydrous ethanol repeatedly, air-drying in a fume hood overnight and finally vacuum drying at $90{ }^{\circ} \mathrm{C}$ for at least $12 \mathrm{~h}$.

Acid-base titration. A toluene solution $\left(\sim 3.3 \times 10^{-3} \mathrm{~g} \mathrm{~mL}^{-1}\right)$ of an accurately weighed mass of the well-dried, purified SCA was titrated in an Erlenmeyer flask against a $\mathrm{KOH}$ ethanol solution from a basic burette, which, with a nominal concentration of $1.0 \times 10^{-2} \mathrm{M}$, was in turn titrated in situ to evaluate its 
effective concentration with a precise amount of potassiumbiphthalate standard of $\sim 1.0 \times 10^{-3} \mathrm{~g} \mathrm{~mL}^{-1}$ in ethanol in another Erlenmeyer flask. For both the titrations, a phenolphthalein indicator solution in an ethanol/water (19/1 v/v) mixed solvent $\left(\sim 1.0 \times 10^{-2} \mathrm{~g} \mathrm{~mL}^{-1}\right)$ was used to identify the first occurrence of a reddish colour as the equivalence point. The CA content (mol\%), $c_{\mathrm{CA}}$, of the SCA was therefore calculated using the following eqn (1),

$$
c_{\mathrm{CA}}=\frac{c V}{c V+\frac{m-M_{\mathrm{CA}} c V}{M}} \times 100 \%
$$

where $c$ is the effective molar concentration $\left(\mathrm{mol} \mathrm{L}^{-1}\right.$ or $\mathrm{M}$ ) of the $\mathrm{KOH}$ ethanol solution, $V$ the volume (L) of the KOH ethanol solution consumed until the equivalence point of the SCA toluene solution titration, $m$ the accurately weighed mass $(\mathrm{g})$ of the well-dried SCA, $M$ and $M_{\mathrm{CA}}$ the molar masses $\left(\mathrm{g} \mathrm{mol}^{-1}\right)$ of styrene and CA units (i.e. 104.15 and 148.16), respectively. To minimise any uncertainty of the result, the median $c_{\mathrm{CA}}$ value from five parallel titrations was taken as the $c_{\mathrm{CA}}$ of the SCA synthesised.

Mechanical testing. The well-dried SCA and PS resins either were plasticated at $200{ }^{\circ} \mathrm{C}$ in a plasticorder (Harbin Harp Electrical Technology Co., Ltd., China, RM-200C) for $6 \mathrm{~min}$ at a screw speed of $80 \mathrm{rpm}$, and then ground into a powder with a laboratory grinder (Yongkang City Boou Hardware Factory, China, 400Y). A laboratory mini injection molder (Shanghai Xinshuo Precision Machinery Co., Ltd., China, Minijet WZS10D) was subsequently used to mold standard impact, tensile and flexural specimens, with the barrel and mold temperatures of $220{ }^{\circ} \mathrm{C}(\mathrm{SCA}) / 200{ }^{\circ} \mathrm{C}(\mathrm{PS})$ and $60{ }^{\circ} \mathrm{C}$, respectively. Finally, the notched impact strength was tested using a Charpy impact tester (Chengde City Testing Machinery Co., Ltd., China, XJJ-50) according to the ISO 179-1 testing standard (specimen type 1). The tensile properties were measured on a universal testing machine (MTS (China), CMT-4202) in the light of the ISO 527 testing standard, using $\sim 2 \mathrm{~mm}$ thick dumbbell-shaped specimens with a gauge length of $20 \mathrm{~mm}$ and a crosshead speed of $2 \mathrm{~mm} \mathrm{~min}^{-1}$; in each of the stress-strain curves, the fracture strength was defined as the tensile strength since none of them exhibited a yield behaviour. The flexural properties were measured on the same machine in accordance with the ISO 178 testing standard, with rectangular specimen dimensions of $80 \times 10 \times 4 \mathrm{~mm}$ and a loading-edge speed of 2 $\mathrm{mm} \min ^{-1}$.

Differential scanning calorimetry (DSC). The glass transition temperature $\left(T_{\mathrm{g}}\right)$ of the SCA resin was measured against the PS resin according to the ISO 11357 testing standard using a differential scanning calorimeter (PerkinElmer, DSC 8000) under a $\mathrm{N}_{2}$ atmosphere of $20 \mathrm{~mL} \mathrm{~min}^{-1}$, upon its calibrations in both temperature and heat flow with an indium standard. For the runs, the well-dried samples $(\sim 3.5 \mathrm{mg})$, encapsulated into a flat-bottomed aluminum pan, were enclosed in the DSC sample cell while an empty pan-lid capsule in the reference cell. Both the cells were then heated from 30 to $200{ }^{\circ} \mathrm{C}$ to minimise any effect(s) of sample preparation history, followed by cooling to $30{ }^{\circ} \mathrm{C}$ and finally heating again to $200{ }^{\circ} \mathrm{C}$, all at a rate of
$20{ }^{\circ} \mathrm{C} \min ^{-1}$. Prior to the sample runs, a baseline was acquired by running the same heating-cooling-heating consecutive cycles of the cells both enclosing an empty pan-lid capsule. Therefore, in the second heating cycle, sample-massnormalised, baseline-subtracted heat flow $\left(\mathrm{W} \mathrm{g}^{-1}\right)$ was plotted against temperature $\left({ }^{\circ} \mathrm{C}\right)$ to constitute the DSC thermograms of the resins for analysis. In either thermogram, the inflection point $\left({ }^{\circ} \mathrm{C}\right)$ of the glass-transition step was identified as the $T_{\mathrm{g}}$.

Heat deflection temperature (HDT) testing. The well-dried SCA and PS resins either were plasticated, then ground, and subsequently injection-molded into standard rectangular $(80 \times$ $10 \times 4 \mathrm{~mm}$ ) specimens using the same procedure as for the flexural testing. The HDT values of the specimens were finally measured in accordance with the ISO 75 testing standard using a heat deflection and Vicat softening temperatures tester (Shenzhen City Aode Saichuang Technology Co., Ltd., China, Auto-RBWK), during their heating in a methyl-silicone oil bath from 25 to $200{ }^{\circ} \mathrm{C}$ at a rate of $120^{\circ} \mathrm{C} \mathrm{h}^{-1}$.

Vicat softening temperature (VST) testing. An $80 \times 10 \times$ $4 \mathrm{~mm}$ rectangle of the SCA and PS resins, prepared using the same procedure as for the flexural testing, was cut into three 10 $\times 10 \times 4 \mathrm{~mm}$ specimens for VST measurement according to the ISO 306 testing standard (method A50). For that purpose, the same tester as for the HDT testing was used to measure the specimens during their heating from 25 to $200{ }^{\circ} \mathrm{C}$.

Thermogravimetric analysis (TGA). The thermal decomposition behaviour of the well-dried SCA resin was studied against the PS resin in accordance with the ASTM E2402 testing standard using a thermogravimetric-differential-thermal simultaneous analyser (TA Instruments, SDT Q600). A small amount $(\sim 3.0 \mathrm{mg})$ of either of the resins was placed in a disposable $\mathrm{Al}_{2} \mathrm{O}_{3}$ crucible on one tray of the thermal balance, which, along with an empty $\mathrm{Al}_{2} \mathrm{O}_{3}$ crucible on the other tray, was then heated from 30 to $600{ }^{\circ} \mathrm{C}$ at a rate of $20{ }^{\circ} \mathrm{C} \mathrm{min}^{-1}$ under a $\mathrm{N}_{2}$ atmo-

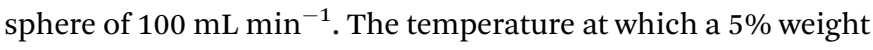
loss of the sample occurred was defined as its thermal decomposition temperature.

Linear thermal expansion coefficient measurement. The measurement was performed in the light of the ASTM E831 testing standard. For that purpose, the SCA and PS resins were compression-molded at $220{ }^{\circ} \mathrm{C}(\mathrm{SCA}) / 200{ }^{\circ} \mathrm{C}$ (PS) and $15 \mathrm{MPa}$ into a $100 \times 90 \times 1 \mathrm{~mm}$ rectangle, which was then cut into three $2 \times 1 \times 1 \mathrm{~mm}$ specimens. A static thermomechanical analyser (TA Instruments-Waters LIC, TMA Q400EM) was subsequently used to measure the length in the thickness direction of the specimens as a function of temperature during their heating from 20 to $80{ }^{\circ} \mathrm{C}$ at a rate of $5{ }^{\circ} \mathrm{C} \mathrm{min}^{-1}$, from which the coefficient of linear thermal expansion, $\alpha_{\mathrm{m}}$, was finally calculated.

Thermal conductivity measurement. $100 \times 90 \times 1 \mathrm{~mm}$ rectangles of either of the SCA and PS resins, prepared using the same procedure as for the $\alpha_{\mathrm{m}}$ measurement, were cut into three specimens of $40 \times 40 \times 1 \mathrm{~mm}$, the thermal conductivity of which was then measured with a portable thermal conductivity meter (Xi'an City Xiaxi Electronic Technology Co., Ltd., China, TC 3000E) according to the ASTM D5930 testing standard. 
Melt strength measurement. The extensional rheological properties of the SCA resin were measured at $220{ }^{\circ} \mathrm{C}$ against the PS resin at $200{ }^{\circ} \mathrm{C}$ using an extensional rheometer (Göttfert, Rheotens 71.97), continuously fed by a high-pressure capillary rheometer (Göttfert, Rheograph 50) with plunger diameter and speed of $15 \mathrm{~mm}$ and $0.4 \mathrm{~mm} \mathrm{~s}^{-1}$, and die diameter and aspect-ratio of $2 \mathrm{~mm}$ and 10, respectively. Accordingly, the extrusion rate of the melt at the die exit was $11.3 \mathrm{~mm} \mathrm{~s}^{-1}$; in the extensional rheometer, the nip rollers were counter-rotated with a roller spacing of $0.4 \mathrm{~mm}$ and a linear acceleration of $12 \mathrm{~mm} \mathrm{~s}^{-2}$; the gauge length (i.e. distance between the die exit and the symmetrical axis between the rollers) was set at $100 \mathrm{~mm}$.

Melt flow rate (MFR) testing. A melt index tester (Chengde City Jinjian Testing Instruments Co., Ltd., China, MFI 1211) was used to measure the MFR of the SCA and PS resins according to the ISO 1133 testing standard, with load and temperature of 5.0 $\mathrm{kg}$ and $200{ }^{\circ} \mathrm{C}$, respectively.

Shear rheometry. The complex viscosity magnitude $\left(\left|\eta^{*}\right|\right)$ of the SCA and PS resins was measured at $200{ }^{\circ} \mathrm{C}$ under a $\mathrm{N}_{2}$ atmosphere as a function of angular frequency $(\omega)\left(10^{-2}-3.8 \times\right.$ $10^{2} \mathrm{rad} \mathrm{s}^{-1}$ ) in the oscillatory shear mode using a rotational rheometer (TA Instruments, DHR-2), with a parallel-plate fixture of $25 \mathrm{~mm}$ in diameter and $1.0 \mathrm{~mm}$ in separation. To ensure linear viscoelastic behaviour of the resin melts, a strainamplitude $(\varepsilon)$ sweep experiment was conducted at $200{ }^{\circ} \mathrm{C}$ and $60 \mathrm{~Hz}$ (i.e. $3.8 \times 10^{2} \mathrm{rad} \mathrm{s}^{-1}$ ) prior to the measurements to determine its safe value to be applied. Before the test, amounts $(\sim 1.4 \mathrm{~g})$ of either resin were compression-molded at $220{ }^{\circ} \mathrm{C}$ (SCA) $/ 200{ }^{\circ} \mathrm{C}$ (PS) and $15 \mathrm{MPa}$ into discoid specimens of $\sim 25 \mathrm{~mm}$ in diameter and $\sim 2 \mathrm{~mm}$ in thickness. On the other hand, the shear viscosities ( $\eta^{\prime}$ 's), at higher shear rates $(\dot{\gamma}$ 's) $\left(\sim 10^{2}-10^{4} \mathrm{~s}^{-1}\right)$, of the resins were measured at $200^{\circ} \mathrm{C}$ by a twinbore capillary rheometer (Malvern Panalytical, Rosand RH10) with one die aspect-ratio $(L / D=10 / 1)$ against the other $(L / D=$ $0.17 / 1$ ) for the Bagley correction. The acquired raw data were analysed by the Rabinowitch correction to obtain the flow-curve results.

Dielectric properties measurement. Discoid $(\varnothing 25 \times 2 \mathrm{~mm})$ specimens, prepared following the same procedure as for the oscillatory-shear specimens, were used to measure the dielectric-constant $(\varepsilon)$ and dielectric-loss $(\tan \delta$ ) of the SCA and PS resins according to the IEC 60250 testing standard. The resonance voltages and resonant capacitors were measured with and without the specimens at $60 \mathrm{~Hz}$ and $1 \mathrm{MHz}$ to evaluate the $\varepsilon$ 's and tan $\delta$ 's, using an LCR digital bridge (Shanghai Tongbei Testing Technologies Co., Ltd., China, TH2826).

Oxygen index testing. Twenty $80 \times 10 \times 4 \mathrm{~mm}$ rectangular specimens, prepared using the same procedure as for the flexural testing, were employed to measure the oxygen index of the SCA and PS resins at RT $\left(23 \pm 2{ }^{\circ} \mathrm{C}\right)$ with an oxygen index tester (Nanjing City Jiangning Analytical Instruments Co., Ltd., China, JF-3) in accordance with the ISO 4589 testing standard. Prior to the test, the equipment was recalibrated, and, during the test, the glass chimney was cleaned constantly to maintain good visibility.
Smoke density testing. The smoke-density-rating value of the SCA was measured against that of the PS using a smoke density tester (Nanjing City Jiangning Analytical Instruments Co., Ltd., China, JCY-2) in the light of the ASTM D2843 testing standard. For the test, an amount $(\sim 30 \mathrm{~g})$ of either resin was compressionmolded at $220{ }^{\circ} \mathrm{C}(\mathrm{SCA}) / 200{ }^{\circ} \mathrm{C}(\mathrm{PS})$ and $15 \mathrm{MPa}$ into a $60 \times 60 \times$ $6 \mathrm{~mm}$ rectangle, which was then cut into three $25 \times 25 \times 6 \mathrm{~mm}$ specimens.

Intrinsic viscosity measurement. Following the ISO 1682-1 testing standard, an Ubbelohde viscometer was used to measure the intrinsic viscosity of the SCA relative to the PS. For the runs, either of the resins was dissolved at $25 \pm 0.1{ }^{\circ} \mathrm{C}$ in toluene to prepare solutions of five decreasing concentrations, i.e. $6 / 6,5 / 6,2 / 3,1 / 2$ and $2 / 5$ of $0.01 \mathrm{~g} \mathrm{~mL}^{-1}$.

Specific gravity measurement. Five $\varnothing 25 \times 2 \mathrm{~mm}$ discoid specimens, prepared following the same procedure as for the oscillatory-shear specimens, were used to measure the specific gravity of the SCA and PS resins with a solid density meter (Beijing City Etnaln Electronic Technologies Co., Ltd., China, ET-320) according to the ASTM D792 testing standard.

Water absorption measurement. $100 \times 90 \times 1 \mathrm{~mm}$ rectangles of either of the SCA and PS resins, prepared using the same procedure as for the $\alpha_{\mathrm{m}}$ measurement, were cut into three $60 \times$ $60 \times 1 \mathrm{~mm}$ specimens, the water absorption of which was then measured upon their immersion in deionised water at $23 \pm 1{ }^{\circ} \mathrm{C}$ for $24 \pm 1 \mathrm{~h}$, in accordance with the ISO 62 testing standard.

To ensure statistical significance, the medians from five parallel results were taken as the data for analysis for the titration, dielectric-property and specific-gravity measurements, from at least eight results for the mechanical-property and MFR tests and from three results for the HDT, VST, $\alpha_{\mathrm{m}}$, thermalconductivity, smoke-density and water-absorption measurements.

\section{Results and discussion}

\section{Reproducibility of the emulsion free-radical copolymerisation}

In Table 1, the (potential SCA) product resin (Table 1(A)) synthesised had molecular weights $\left(\bar{M}_{\mathrm{n}}, \bar{M}_{\mathrm{w}}, M_{\mathrm{p}}, \bar{M}_{\mathrm{z}}\right.$ and $\left.\bar{M}_{\mathrm{z}+1}\right)$ and their distributions $\left(D_{1}, D_{2}\right.$ and $\left.D_{3}\right)$ all comparable to those of the (commercial) PS. More synthetic batches (Table 1(B-F)) of the product resin were all not changed considerably in molecular weights and their distributions compared with Table 1(A), indicating that the polymerisation process was controlled at high reproducibility.

\section{Evidence for the successful synthesis of SCA}

Shown in Fig. 1 is the FTIR absorption spectrum (Trace 2) of the product resin as opposed to that (Trace 1) of the PS. In Trace 1 for the PS, the absorption bands at 3080, 3059 and $3025 \mathrm{~cm}^{-1}$ were attributed to the stretches of the phenyl $\mathrm{C}-\mathrm{H}$ bonds, ${ }^{27}$ the 2923 and $2850 \mathrm{~cm}^{-1}$ bands, respectively, to the antisymmetric and symmetric stretches of the $-\mathrm{CH}_{2}-$ groups, ${ }^{28}$ the 1943,1872 , 1803,1745 and $1664 \mathrm{~cm}^{-1}$ bands to the $\mathrm{C}-\mathrm{C}$ and $\mathrm{C}-\mathrm{H}$ overtone and combination stretches of the phenyl groups, ${ }^{29}$ the 1600 , 1492 and $1448 \mathrm{~cm}^{-1}$ absorption peaks to the stretches of the 
Table 1 Molecular weights and their distributions, measured from six parallel batches of polymerisations, of supposedly a poly(styrene-rancinnamic acid) (SCA), i.e. polystyrene (PS) copolymerised with a small amount of cinnamic acid, compared with those of a commercial PS

\begin{tabular}{|c|c|c|c|c|c|c|c|c|c|}
\hline PS & $-^{a}$ & 60000 & 198000 & 151000 & 414000 & 611000 & 3.3 & 2.1 & 3.1 \\
\hline \multirow{3}{*}{ SCA } & B & 64000 & 209000 & 155000 & 439000 & 656000 & 3.3 & 2.1 & 3.1 \\
\hline & $\mathrm{C}$ & 30000 & 224000 & 188000 & 483000 & 698000 & 7.2 & 2.2 & 3.1 \\
\hline & $\mathrm{D}$ & 30000 & 210000 & 174000 & 463000 & 681000 & 6.9 & 2.2 & 3.3 \\
\hline
\end{tabular}

phenyl $\mathrm{C}-\mathrm{C}$ bonds (i.e. phenyl skeleton vibrations), ${ }^{27,30}$ the $1378 \mathrm{~cm}^{-1}$ peak to the in-plane rocking of the aliphatic $\mathrm{CH}$ groups in the main chain, ${ }^{29}$ the 1069 and $1026 \mathrm{~cm}^{-1}$ and 754 and $697 \mathrm{~cm}^{-1}$ peaks, respectively, to the in-plane and out-ofplane bending of the phenyl $\mathrm{C}-\mathrm{H}$ bonds. ${ }^{31}$ Compared with Trace 1, Trace 2 for the product resin exhibited, in addition to all the above featured absorptions, new peaks at 1744 and $1703 \mathrm{~cm}^{-1}$ characteristic of the stretches of free and dimeric carboxyl $\mathrm{C}=\mathrm{O}$ bonds, respectively. ${ }^{13,32}$ Right around there, part of the phenyl overtone and combination stretches (at 1745 and $1664 \mathrm{~cm}^{-1}$ ) were found to be overshadowed due to their weaker intensities, which does not prevent one inferring that the 1744 and $1703 \mathrm{~cm}^{-1}$ bands were indeed new from the introduced carboxyls.

Contingent upon the reactivity ratios of styrene and CA monomers, the product resin might primarily comprise one of three possible species, PS-poly(cinnamic acid) (PCA) blend, PS and SCA. From the resin's FTIR sample reprecipitated from toluene into ethanol (cf. Par. 2, Section 2.3), free CA and/or PCA molecules, if any, were effectively eliminated by the dissolving ethanol. Therefore, if it had been a PS-PCA blend or PS, the resin would have demonstrated an FTIR spectrum basically of neat PS (Trace 1, Fig. 1), which was impossible. In other words, upon the removal of any free (i.e. unpolymerised) CA from it, the resin actually displayed an FTIR spectrum (Trace 2, Fig. 1) bearing the carboxyls' characteristic bands, which proves success in the copolymerisation of CA into PS to form an SCA. More quantitatively, the CA content of the SCA was evaluated from eqn (1) by acid-base titration to be $6.8 \mathrm{~mol} \%$, which was indeed significant considering the CA-comonomer feed ratio of $10 \mathrm{wt} \%$ ( $\sim 7.2 \mathrm{~mol} \%)$. This value, along with the SCA's typical $\bar{M}_{\mathrm{w}}$ and $\bar{M}_{\mathrm{w}} / \bar{M}_{\mathrm{n}}$ against those of the PS (Table 1), is listed in Table 2.

\section{Mechanical properties of the SCA}

As shown in Table 2, the Charpy notched impact strength, tensile and flexural properties (primarily modulus and strength) of the SCA were all enhanced compared with the (commercial) PS, which may arise from, besides the volume fraction (6.8 $\mathrm{mol} \%$ ) of rigid CA comonomer, essentially the reversible hydrogen bond cross-links (i.e. dimeric carboxyls) introduced by the copolymerisation of CA. Particularly worth noting is that the

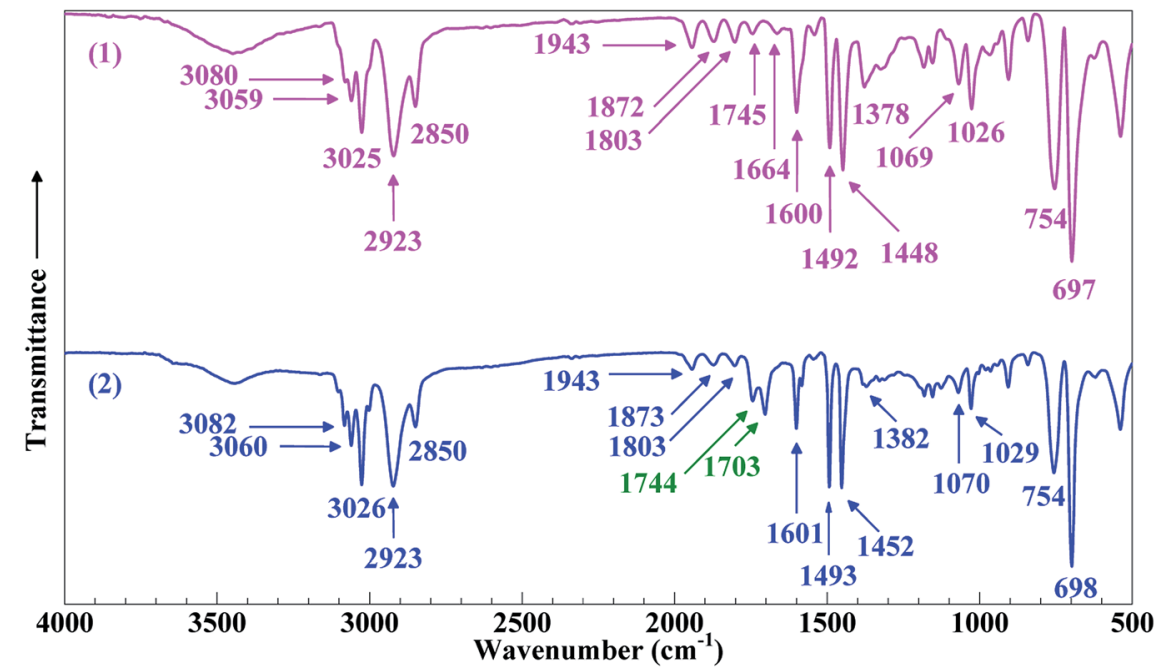

Fig. 1 Fourier transform infrared (FTIR) absorption spectra of (1) a commercial polystyrene (PS) and (2) a resin, supposedly poly(styrene-rancinnamic acid), laboratory synthesised by emulsion free-radical copolymerisation of styrene with a small amount (10 wt\%) of cinnamic acid. 
Table 2 Overall properties of a poly(styrene-ran-cinnamic acid) (SCA) resin, i.e. polystyrene (PS) copolymerised with 6.8 mol\% of cinnamic acid, compared with those of a commercial PS resin

\begin{tabular}{|c|c|c|c|c|c|}
\hline \multirow[b]{2}{*}{ Properties } & \multirow[b]{2}{*}{ Parameter } & \multirow[b]{2}{*}{ Testing method } & \multirow[b]{2}{*}{ Testing condition(s) } & \multicolumn{2}{|l|}{ Value } \\
\hline & & & & PS & SCA \\
\hline \multirow[t]{3}{*}{ Structural } & Cinnamic-acid (CA) content (mol\%) & $-^{a}$ & $-^{a}$ & $-^{c}$ & 6.8 \\
\hline & Weight-average molecular weight $\left(\bar{M}_{\mathrm{w}}\right)$ & $-^{b}$ & $35^{\circ} \mathrm{C}$ & 198000 & 217000 \\
\hline & Polydispersity index $\left(\bar{M}_{\mathrm{w}} / \bar{M}_{\mathrm{n}}\right)$ & $-^{b}$ & $35^{\circ} \mathrm{C}$ & 3.3 & 3.6 \\
\hline \multirow[t]{6}{*}{ Mechanical } & Charpy notched impact strength $\left(\mathrm{kJ} \mathrm{m}^{-2}\right)$ & ISO $179-1$ & $23 \pm 2{ }^{\circ} \mathrm{C}, 2 \mathrm{~mm} \min ^{-1}$ & 5.3 & 7.8 \\
\hline & Young's modulus (MPa) & ISO 527 & $23 \pm 2{ }^{\circ} \mathrm{C}, 2 \mathrm{~mm} \mathrm{~min}^{-1}$ & $2.8 \times 10^{2}$ & $3.7 \times 10^{2}$ \\
\hline & Tensile strength (MPa) & ISO 527 & $23 \pm 2{ }^{\circ} \mathrm{C}, 2 \mathrm{~mm} \min ^{-1}$ & 52.3 & 57.1 \\
\hline & Elongation at break (\%) & ISO 527 & $23 \pm 2{ }^{\circ} \mathrm{C}, 2 \mathrm{~mm} \min ^{-1}$ & 10.5 & 9.7 \\
\hline & Flexural modulus (MPa) & ISO 178 & $23 \pm 2{ }^{\circ} \mathrm{C}, 2 \mathrm{~mm} \min ^{-1}$ & $2.1 \times 10^{4}$ & $2.4 \times 10^{4}$ \\
\hline & Flexural strength (MPa) & ISO 178 & $23 \pm 2{ }^{\circ} \mathrm{C}, 2 \mathrm{~mm} \mathrm{~min}^{-1}$ & 138.4 & 167.6 \\
\hline \multirow[t]{6}{*}{ Thermal } & Glass transition temperature $\left({ }^{\circ} \mathrm{C}\right)$ & ISO 11357 & $20^{\circ} \mathrm{C} \min ^{-1}$ & 95.2 & 117.0 \\
\hline & Heat deflection temperature $\left({ }^{\circ} \mathrm{C}\right)$ & ISO 75 & $0.45 \mathrm{MPa}, 120^{\circ} \mathrm{C} \mathrm{h}^{-1}$ & 87.6 & 108.0 \\
\hline & Vicat softening temperature $\left({ }^{\circ} \mathrm{C}\right)$ & ASTM D1525 & $10 \mathrm{~N}, 50^{\circ} \mathrm{C} \mathrm{h}^{-1}$ & 96.0 & 118.3 \\
\hline & $\begin{array}{l}\text { Thermal decomposition temperature } \\
\left({ }^{\circ} \mathrm{C}\right)\end{array}$ & ASTM E2402 & $20^{\circ} \mathrm{C} \min ^{-1}$ & $391.9^{d}$ & $360.1^{d}$ \\
\hline & $\begin{array}{l}\text { Linear thermal expansion coefficient } \\
\left(\mu \mathrm{m} \mathrm{m}{ }^{-1}{ }^{\circ} \mathrm{C}^{-1}\right)\end{array}$ & ASTM E831 & $25-75{ }^{\circ} \mathrm{C}, 5{ }^{\circ} \mathrm{C} \min ^{-1}$ & 78.4 & 79.5 \\
\hline & Thermal conductivity $\left(\mathrm{W} \mathrm{m}{ }^{-1} \mathrm{~K}^{-1}\right.$ ) & ASTM D5930 & $23 \pm 0.1^{\circ} \mathrm{C}$ & 0.160 & 0.165 \\
\hline \multirow[t]{3}{*}{ Processing } & Melt strength ${ }^{e}(\mathrm{~Pa} \mathrm{~s})$ & $-^{f}$ & $0.5 \mathrm{~s}^{-1}, 220^{\circ} \mathrm{C}(\mathrm{SCA}) / 200^{\circ} \mathrm{C}(\mathrm{PS})$ & $4.2 \times 10^{4}$ & $3.3 \times 10^{5}$ \\
\hline & Melt flow rate (g per $10 \mathrm{~min}$ ) & ISO 01133 & $200{ }^{\circ} \mathrm{C}, 5.0 \mathrm{~kg}$ & 6.9 & 0.6 \\
\hline & Shear viscosity (Pa s) & $\_^{g}$ & $200{ }^{\circ} \mathrm{C}, 10^{3} \mathrm{~s}^{-1}$ & 101.7 & 278.9 \\
\hline \multirow[t]{4}{*}{ Dielectric } & Dielectric constant & IEC 60250 & $60 \mathrm{~Hz}$ & 2.8 & 2.8 \\
\hline & & & $1 \mathrm{MHz}$ & 2.8 & 2.7 \\
\hline & Dielectric loss & IEC 60250 & $60 \mathrm{~Hz}$ & $3.7 \times 10^{-3}$ & $3.3 \times 10^{-3}$ \\
\hline & & & $1 \mathrm{MHz}$ & $0.6 \times 10^{-3}$ & $1.6 \times 10^{-3}$ \\
\hline \multirow[t]{2}{*}{ Fire } & Oxygen index (vol\%) & ISO 4589 & $23 \pm 2{ }^{\circ} \mathrm{C}$ & 19.7 & 19.9 \\
\hline & Density of smoke (\%) & ASTM D2843 & $23 \pm 2{ }^{\circ} \mathrm{C}$ & 88.8 & 92.5 \\
\hline \multirow[t]{3}{*}{ Other physical } & Intrinsic viscosity $\left(\mathrm{dL} \mathrm{g}^{-1}\right)$ & ISO 1628-1 & $25 \pm 0.1^{\circ} \mathrm{C}$, toluene & $8.4 \times 10^{-2}$ & $2.6 \times 10^{-2}$ \\
\hline & Specific gravity & ASTM D792 & $23 \pm 2{ }^{\circ} \mathrm{C}$ & 1.05 & 1.07 \\
\hline & Water absorption (wt\%) & ISO 62 & $23 \pm 2{ }^{\circ} \mathrm{C}, 24 \mathrm{~h}$ & 0.06 & 0.47 \\
\hline $\begin{array}{l}{ }^{a} \text { Measured by } \\
\text { a phenolphthal } \\
\text { (GPC), with tetr } \\
\text { applicable. }{ }^{d} \mathrm{M} \\
\text { weight loss def } \\
\text { curves. }^{f} \text { Measu } \\
\text { acceleration of } \\
\text { capillary rheom }\end{array}$ & $\begin{array}{l}\text { tion of a toluene solution of the purified } \\
\text { solution in an ethanol/water }(19 / 1 \mathrm{v} / \mathrm{v}) \mathrm{mi} \\
\text { drofuran as the eluent at a constant flow } \\
\text { ared by thermogravimetric analysis (TGA) } \\
\text { las the } T_{\mathrm{d} \cdot}{ }^{e} \text { Characterised by the extensio } \\
\text { at } 200^{\circ} \mathrm{C}(\mathrm{PS}) / 220^{\circ} \mathrm{C} \text { (SCA) by an extensio } \\
\text { am s }{ }^{-2} \text {, and a gauge length }(\text { i.e. } \text { distance be } \\
\text { r with one die aspect-ratio }(L / D=10 / 1) \text { ag }\end{array}$ & $\begin{array}{l}\text { A against a } \mathrm{KOH} \text { e } \\
\text { solvent as the ir } \\
\text { e of } 1.0 \mathrm{~mL} \mathrm{~min}^{-1} \\
\text { a heating rate of } \\
1 \text { viscosity }\left(\eta_{\mathrm{e}}\right) \text { at } \\
1 \text { rheometer, with }\end{array}$ & $\begin{array}{l}\text { nanol solution titrated by potassium } \\
\text { icator. }{ }^{b} \text { Measured at } 35{ }^{\circ} \mathrm{C} \text { by gel } \mathrm{p} \\
\text { ind monodisperse PS resins up to } 1 \\
{ }^{\circ} \mathrm{C} \mathrm{min}^{-1} \text { under a } \mathrm{N}_{2} \text { atmosphere, } \\
\text { practical extensional strain rate }(\dot{\varepsilon}) \\
\text { die-exit melt extrusion rate of } 11.3 \\
\text { the nip rollers) of } 100 \mathrm{~mm} .{ }^{g} \text { Meast } \\
0.17 / 1 \text { ) for the Bagley correction. }\end{array}$ & $\begin{array}{l}\text { biphthalate } \\
\text { rmeation ch } \\
\text { ok as the st } \\
\text { ith the tem } \\
0.5 \mathrm{~s}^{-1} \text { in } \mathrm{t} \\
\mathrm{m} \mathrm{s}^{-1} \text {, a nip } \\
\text { ed at } 200^{\circ} \mathrm{C}\end{array}$ & $\begin{array}{l}\text { Indard, with } \\
\text { matography } \\
\text { dards. }{ }^{c} \text { Not } \\
\text { ature at } 5 \% \\
\eta_{\mathrm{e}} v s . \dot{\varepsilon} \text { flow } \\
\text { ollers' linear } \\
\text { a twin-bore }\end{array}$ \\
\hline
\end{tabular}

impact toughness of the SCA was significantly improved by $47.2 \%$ against the PS. According to the craze theory, ${ }^{33,34}$ this might be associated with balanced initiation of new crazes by unzipping (i.e. de-hydrogen-bonding) of SCA segments and stabilisation of preexisting crazes propagation by segmental zipping (i.e. re-hydrogen-bonding), both of which contributed to absorption of impact energy.

\section{Thermal properties of the SCA}

Fig. 2 gives the DSC thermograms of the SCA and PS, from which their $T_{\mathrm{g}}{ }^{\prime}$ 's were analysed as summarised in Table 2 ; it is seen that the $T_{\mathrm{g}}\left(117.0^{\circ} \mathrm{C}\right)$ of the SCA was noticeably $\left(\sim 20^{\circ} \mathrm{C}\right)$ higher than that $\left(95.2^{\circ} \mathrm{C}\right)$ of the PS. Also observed from Table 2 is that the HDT and VST of the SCA were both significantly enhanced until 108.0 and $118.3{ }^{\circ} \mathrm{C}$, respectively, compared with those $\left(87.6\right.$ and $96.0^{\circ} \mathrm{C}$ ) of the PS. The large increases in the $T_{\mathrm{g}}$, HDT and VST indicate that the heat resistance of the SCA was greatly improved as opposed to the PS. Again, this may be basically due to the $6.8 \mathrm{~mol} \%$ of carboxyl groups incorporated into the SCA by copolymerisation: the steric hindrance of the pendant carboxyls limited the internal rotation of the SCA backbone chains; more remarkably, the hydrogen bond crosslinking applied by dimeric carboxyls strengthened the SCA chain-segmental interactions. Both of these led to rigidification of the SCA chains that constituted pronounced enhancement of the SCA heat resistance.

It can be seen from Fig. 3 that the thermal decomposition temperature $\left(360.1^{\circ} \mathrm{C}\right)$ of the SCA was $\sim 30^{\circ} \mathrm{C}$ lower than the PS $\left(391.9{ }^{\circ} \mathrm{C}\right.$ ), the results of which are listed in Table 2 . This may originate from higher chemical activity of the SCA bearing carboxyl groups, which were subject to thermal decomposition into $\mathrm{CO}_{2}$. Finally, as shown in Table 2, the linear thermal expansion coefficient $\left(\alpha_{\mathrm{m}}\right)$ and thermal conductivity $(\lambda)$ of the $\mathrm{SCA}, 79.5 \mu \mathrm{m} \mathrm{m}^{-1}{ }^{\circ} \mathrm{C}^{-1}$ and $0.165 \mathrm{~W} \mathrm{~m}^{-1} \mathrm{~K}^{-1}$ respectively, were 


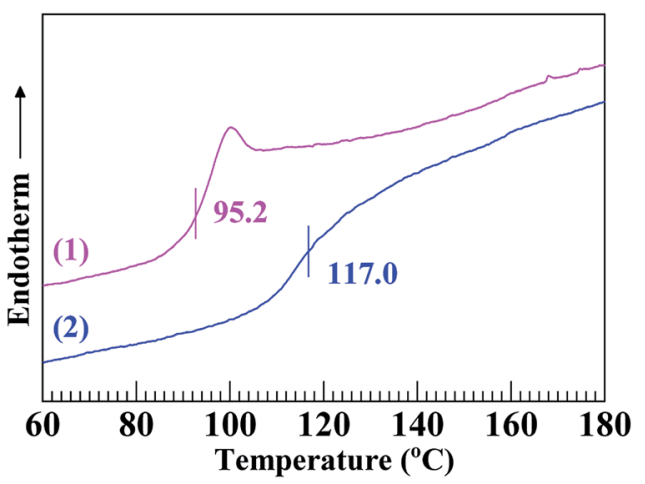

Fig. 2 Differential scanning calorimetry (DSC) thermograms in the second heating cycle at a rate of $20{ }^{\circ} \mathrm{C} \mathrm{min}^{-1}$ for (1) a commercial polystyrene (PS) and (2) a poly(styrene-ran-cinnamic acid) (SCA), i.e. PS copolymerised with 6.8 mol\% of cinnamic acid.

comparable to those $\left(78.4 \mu \mathrm{m} \mathrm{m}^{-1}{ }^{\circ} \mathrm{C}^{-1}\right.$ and $\left.0.160 \mathrm{~W} \mathrm{~m}^{-1} \mathrm{~K}^{-1}\right)$ of the PS, suggesting that the $\alpha_{\mathrm{m}}$ and $\lambda$ of the PS were both little changed upon the carboxylation modification.

\section{Melt strength of the SCA}

In the molten states, with melt flow temperatures $\left(T_{\mathrm{f}}\right)$ defined by HDT $+112{ }^{\circ} \mathrm{C}$, of the PS $\left(T_{\mathrm{f}}=200^{\circ} \mathrm{C}\right)$ and SCA $\left(T_{\mathrm{f}}=220^{\circ} \mathrm{C}\right)$, the drawdown force $(F) v s$. draw ratio $(V)$ (Fig. 4a), extensional stress $\left(\sigma_{\mathrm{e}}\right)$ vs. $V$ (Fig. $\left.4 \mathrm{~b}\right)$ and extensional viscosity $\left(\eta_{\mathrm{e}}\right)$ vs. extensional strain rate $(\dot{\varepsilon})$ (Fig. $4 \mathrm{c}$ ) curves demonstrate that the $F, \sigma_{\mathrm{e}}$ and $\eta_{\mathrm{e}}$ of the SCA were all significantly larger than those of the PS, suggesting a markedly enhanced melt strength of the SCA compared with the PS. This is presumably owing to the reversible hydrogen bond cross-links as well as rigid CA inclusion; the former significantly strengthened the chain-segmental interactions, which in turn would cause a much milder decrease in the SCA melt strength with increasing temperature. In other words, compared with the PS, the SCA may exhibit a considerably broadened temperature window required for the appropriate melt strengths for stabilisation of its foaming (i.e. styrofoam

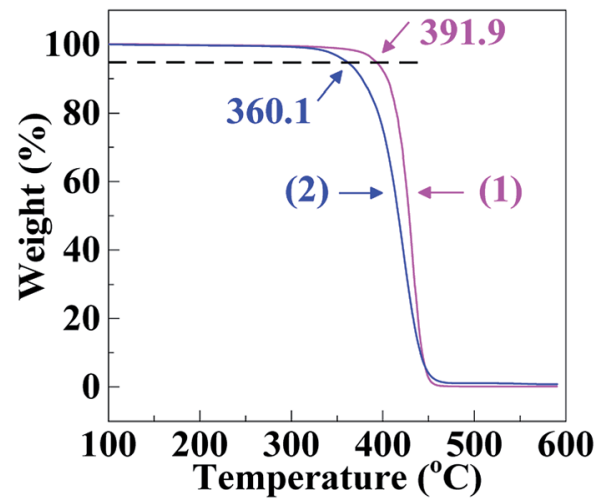

Fig. 3 Thermogravimetric analysis (TGA) thermograms at a rate of $20{ }^{\circ} \mathrm{C} \mathrm{min}^{-1}$ for (1) a commercial polystyrene (PS) and (2) a poly(styrene-ran-cinnamic acid) (SCA), i.e. PS copolymerised with $6.8 \mathrm{~mol} \%$ of cinnamic acid.
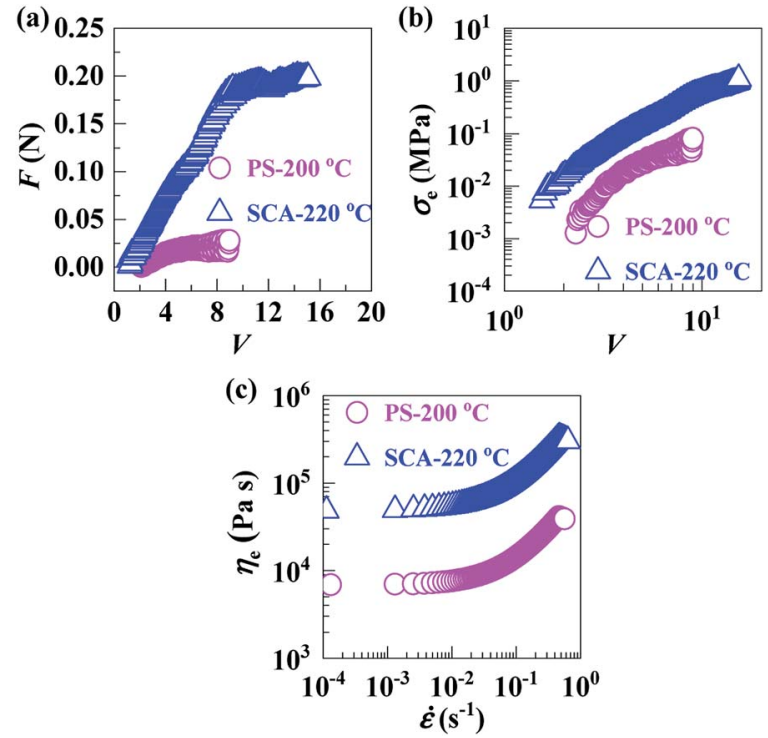

Fig. 4 (a) Drawdown forces ( $\left.F^{\prime} s\right)$ and (b) extensional stresses ( $\left.\sigma_{\mathrm{e}}{ }^{\prime} \mathrm{s}\right)$ as functions of draw ratio $(V)$ and (c) extensional viscosities $\left(\eta_{\mathrm{e}}\right.$ 's) as functions of extensional strain rate $(\dot{\varepsilon})$, for (o) a commercial polystyrene (PS) at $200{ }^{\circ} \mathrm{C}$ and $(\triangle)$ a poly(styrene-ran-cinnamic acid) (SCA), i.e. PS copolymerised with $6.8 \mathrm{~mol} \%$ of cinnamic acid, at $220^{\circ} \mathrm{C}$.

production) operations; this constitutes a more essential sense of the SCA melt-strength improvement. As a typical measure of melt strength, the $\eta_{\mathrm{e}}\left(3.3 \times 10^{5} \mathrm{~Pa} \mathrm{~s}\right)$ at a practical meltprocessing (e.g. foaming) $\dot{\varepsilon}$ of $0.5 \mathrm{~s}^{-1}$ for the SCA is given against the PS $\left(4.2 \times 10^{4} \mathrm{~Pa}\right.$ s $)$ in Table 2 .

\section{Processability of the SCA}

Compared with the PS, the apparently sharply-reduced MFR of the SCA (0.6 vs. $6.9 \mathrm{~g} 10^{-1} \mathrm{~min}^{-1}$ ) shown in Table 2 does not necessarily indicate that the processing fluidity of the SCA was dramatically deteriorated at the same typical melt-processing shear rate. This is because the greatly increased viscosity of the SCA originated from not only the hydrogen bond crosslinking as well as rigid volume-fraction of CA, but, preponderantly, its much smaller shear rate (and thus shear thinning) under the same load applied during the MFR testing. (a)

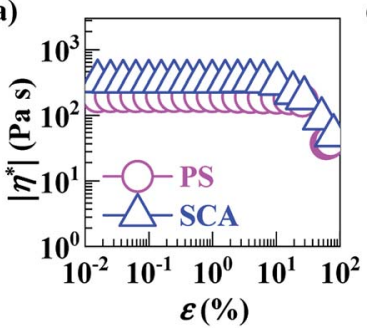

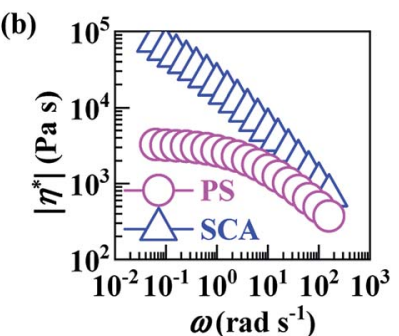

Fig. 5 (a) Complex viscosity magnitudes ( $\left|\eta^{*}\right|$ 's) as functions of strain amplitude $(\varepsilon)$ at $200{ }^{\circ} \mathrm{C}$ and $60 \mathrm{~Hz}$, and (b) $\left|\eta^{*}\right|$ 's as functions of angular frequency $(\omega)$ at $200{ }^{\circ} \mathrm{C}$ and an $\varepsilon$ of $0.1 \%$, for (o) a commercial polystyrene (PS) and $(\Delta)$ a poly(styrene-ran-cinnamic acid) (SCA), i.e. PS copolymerised with $6.8 \mathrm{~mol} \%$ of cinnamic acid. 
As can be seen from Fig. 5a, the SCA and PS were both in the linear viscoelastic region below $\varepsilon^{\prime}$ s of $\sim 5 \%$; their $\left|\eta^{*}\right|$ vs. $\omega$ behaviours were therefore compared at a small $\varepsilon$ of $0.1 \%$ ensuring linear viscoelasticity (Fig. 5b), which were then reduced to $\eta v s . \dot{\gamma}\left(10^{-1}-10^{2} \mathrm{~s}^{-1}\right)$ relationships (Fig. 6) according to the Cox-Merz rule. The capillary rheology at higher $\dot{\gamma}$ 's $\left(10^{2}-\right.$ $10^{4} \mathrm{~s}^{-1}$ ) was subsequently measured as well, and finally added to Fig. 6 to form flow mastercurves of the SCA and PS. It is seen that, over the entire range of $\dot{\gamma}$ 's investigated, the $\eta$ 's of the SCA at $200{ }^{\circ} \mathrm{C}$ were higher than the PS presumably from its hydrogen bond cross-linking and rigid CA copolymerisation combined effects. Further, at low $\dot{\gamma}$ 's, the SCA displayed a stronger shearthinning behaviour than the PS since its hydrogen bond crosslinks were inclined to dissociate upon shearing, while, at the higher $\dot{\gamma}$ 's, the SCA and PS exhibited similar shear-thinning behaviours. Under these circumstances, the $\eta$ (e.g. $278.9 \mathrm{~Pa} \mathrm{~s}$ ) of the SCA at a typical melt-processing $\dot{\gamma}\left(e . g .10^{3} \mathrm{~s}^{-1}\right)$ was just a little higher relative to the PS (e.g. 101.7 Pa s) (Table 2), which constitutes an inheritance of the PS's excellent processability by the SCA without significant compromisation.

\section{Dielectric properties of the SCA}

At a low frequency (e.g. $60 \mathrm{~Hz}$ ), the electrical insulation ( $\varepsilon$ of 2.8 and $\tan \delta$ of $3.3 \times 10^{-3}$ ) of the SCA was comparable to the PS ( $\varepsilon$ of 2.8 and $\tan \delta$ of $3.7 \times 10^{-3}$ ); at a higher frequency (e.g. 1 $\mathrm{MHz}$ ), the $\varepsilon$ (2.7) of the SCA was still approximate to the PS (2.8) whereas the $\tan \delta\left(1.6 \times 10^{-3}\right)$ of the SCA larger than the PS $(0.6$ $\times 10^{-3}$ ), indicating a deterioration of the SCA's electrical insulation compared with the PS (Table 2). In other words, the $\varepsilon^{\prime}$ 's of the SCA were equivalent to the PS at both the frequencies (Table 2 ), which may result from the hydrogen bond cross-links of the former that essentially repressed the polarisation orientation of its carboxyls. ${ }^{35,36}$ However, the $\tan \delta$ of the SCA remained close to the PS at the low frequency while became larger than the PS at the higher frequency (Table 2), the latter of which should also

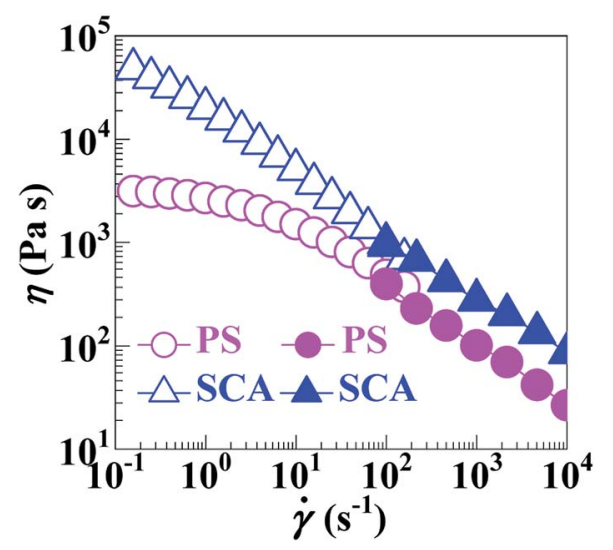

Fig. 6 Shear-viscosity $(\eta)$ vs. shear-rate $(\dot{\gamma})$ flow mastercurves at $200^{\circ} \mathrm{C}$ for $(0, \bullet)$ a commercial polystyrene (PS) and $(\Delta, \Lambda)$ a poly(styreneran-cinnamic acid) (SCA), i.e. PS copolymerised with $6.8 \mathrm{~mol} \%$ of cinnamic acid. Wherein, the data points $(0, \Delta)$ are derived from oscillatory-shear rotational rheometry and the other data points $(\bullet, \Delta)$ are obtained from capillary rheometry. be associated with the weaker mobility of the SCA chain segments constrained by their hydrogen bond cross-links.

\section{Fire properties of the SCA}

The oxygen index (19.9) of the SCA was comparable to the PS (19.7), and the density of smoke (92.5) of the SCA a bit higher than the PS (88.8) (Table 2). These results seem to discover that the fire properties of the SCA were basically in the proximity of the PS.

\section{Other physical properties of the SCA}

The intrinsic viscosity $\left(2.6 \times 10^{-2} \mathrm{dL}^{-1}\right)$ of the SCA was considerably lower than the PS $\left(8.4 \times 10^{-2} \mathrm{dL} \mathrm{g}^{-1}\right)$ (Table 2), which probably arises from the hydrogen bond cross-links of the former shrinking its chain segments in radial size. The specific gravity (1.07) of the SCA was almost equal to the PS (1.05) (Table 2). And the water absorption (0.47) of the SCA was significantly increased relative to the PS (0.06) (Table 2), obviously due to its introduction of $6.8 \mathrm{~mol} \%$ of polar, hydrophilic carboxy groups.

\section{Conclusions}

Styrene is copolymerised via emulsion radical polymerisation with cinnamic acid (CA), a green compound to produce a modified polystyrene (PS), poly(styrene-ran-cinnamic acid) (SCA), of comparable $\bar{M}_{\mathrm{w}}$ of $\sim 200000$ to commercial PS bearing $6.8 \mathrm{~mol} \%$ of CA. Compared with commercial PS, the SCA displays significantly improved impact toughness (by $47.2 \%$ ), heat resistance (glass-transition, heat deflection and Vicat softening temperatures all by $\sim 20{ }^{\circ} \mathrm{C}$ ) and melt strength (extensional viscosity by one order of magnitude, and foaming temperature window). Regarding other properties, despite decreases in its thermal decomposition stability, electrical insulation and moisture resistance, the SCA exhibits mechanical strengths, linear thermal expansion coefficient, thermal conductivity, processability, fire properties, specific gravity, etc. all basically approximate to commercial PS. These overall properties of the SCA relative to commercial PS, from a chain topological viewpoint, are all attributed to its rigid volumefraction of $\mathrm{CA}$ and/or hydrogen bond cross-linking from dimerisation of CA carboxyls. As a modified version of PS, the SCA demonstrates both-improved, balanced impact toughness and heat resistance superior to commercial HIPS, SMA, SAN, SMMA and ABS, as well as enhanced melt strength, which potentially extend its styrofoam and commodity applications.

\section{Conflicts of interest}

There are no conflicts of interest to declare.

\section{Acknowledgements}

We acknowledge with gratitude that this work was financially supported by the Overseas High-level Talents Scientific-research Starting Fund of Hubei University of Technology, China 
(Contract no. HBUT-science-[2005]2), as well as by the Select Overseas Chinese Scholars Science and Technology Activities Foundation of the Ministry of Human Resources and Social Security of China (Grant no. [2013]277) and the Natural Science Foundation of the Hubei Province of China (Contract nos. 2014CFA094 and 2016CFB205).

\section{References}

1 S. B. Neoh and A. S. Hashim, J. Appl. Polym. Sci., 2004, 93, 1660.

2 J. L. Amos, J. L. McCurdy and O. R. Mclntire, US Pat., US18157650A, 1954.

3 G. H. Gao, C. Zhou, H. D. Yang and H. X. Zhang, J. Appl. Polym. Sci., 2007, 103, 738.

4 S. Shaw and R. P. Singh, J. Appl. Polym. Sci., 2010, 40, 701.

5 A. Z. Aroğuz and B. M. Baysal, J. Appl. Polym. Sci., 2015, 75, 225.

6 Y. Gao, L. Liu and Z. Zhang, Acta Mech. Solida Sin., 2009, 22, 555.

7 S. P. Thomas and S. Thomas, J. Phys. Chem. C, 2009, 113, 97. 8 S. L. Qiu, W. Z. Hu, B. Yu, B. H. Yuan, Y. L. Zhu, S. H. Jiang, B. B. Wang, L. Song and Y. Hu, Ind. Eng. Chem. Res., 2015, 54, 3309.

9 O. Bera, B. Pilić, J. Pavličević, M. Jovičić, B. Holló, K. M. Szécsényi and M. Špirkova, Thermochim. Acta, 2011, $515,1$.

10 G. H. Chen, D. J. Wu, W. G. Weng, B. He and W. L. Yan, Polym. Int., 2001, 50, 980.

11 T. P. Selvin, J. Kuruvilla and T. Sabu, Mater. Lett., 2004, 58, 281.

12 A. P. Mathew, S. Packirisamy and S. Thomas, Polym. Degrad. Stab., 2001, 72, 423.

13 M. P. Tsyurupa and V. A. Davankov, React. Funct. Polym., 2002, 53, 193.

14 E. R. Moore, Ind. Eng. Chem. Prod. Res. Dev., 1986, 25, 315. 15 T. Alfrey and E. Lavin, J. Am. Chem. Soc., 1945, 67, 2044.

16 M. Narayana, H. Keskkula and J. E. Mason, US Pat., US3641212DA, 1972.
17 N. V. Tsarevsky, T. Sarbu, B. Göbelt and K. Matyjaszewski, Macromolecules, 2002, 35, 6142.

18 M. E. Fowler, H. Keskkula and D. R. Paul, Polymer, 1987, 28, 1703.

19 G. D. Liu, X. C. Li, L. C. Zhang, X. W. Qu, P. G. Liu, L. T. Yang and J. G. Gao, J. Appl. Polym. Sci., 2002, 83, 417.

20 F. R. Mayo and F. M. Lewis, J. Am. Chem. Soc., 1994, 66, 1594. 21 P. Bataille and F. Granger, Polym. Eng. Sci., 1985, 25, 1164.

22 B. J. P. Jansen, S. Rastogi, H. E. H. Meijer and P. J. Lemstra, Macromolecules, 2001, 34, 3998.

23 L. E. Dlay, US Pat., US54612555A, 1961.

24 W. Brostow, H. E. H. Lobland and S. Khoja, Mater. Lett., 2015, 159, 478.

25 Food and Drug Administration, Food additives permitted for direct addition to food for human consumption, Food and Drug Administration, Washington, DC, 2018.

26 R. P. Sijbesma, F. H. Beijer, L. Brunsveld, B. J. B. Folmer, J. H. K. K. Hirschberg, R. F. M. Lange, J. K. L. Lowe and E. W. Meijer, Science, 1997, 278, 1601.

27 S. H. Kim, W. K. Son, Y. J. Kim, E. G. Kang, D. W. Kim, C. W. Park, W. G. Kim and H. J. Kim, J. Appl. Polym. Sci., 2003, 88, 595.

28 G. M. Chen, S. H. Liu, S. J. Chen and Z. N. Qi, Macromol. Chem. Phys., 2001, 202, 1189.

29 R. A. Nyquist, Appl. Spectrosc., 1984, 38, 264.

30 V. K. Thakur, E. J. Tan, M. F. Lin and P. S. Lee, Polym. Chem., 2011, 2, 2000.

31 A. A. Bhutto, D. Vesely and B. J. Gabrys, Polymer, 2003, 44, 6627.

32 J. Dong, Y. Ozaki and K. Zakashima, Macromolecules, 1997, 30, 1111.

33 C. B. Bucknall, Polymer, 2007, 48, 1030.

34 W. J. Si, W. Q. Yuan, Y. D. Li, Y. K. Chen and J. B. Zeng, Polym. Test., 2018, 65, 249.

35 I. M. El-Anwar, O. M. El-Nabawy, S. A. El-Hennwii and A. H. Salama, Chaos, Solitons Fractals, 2000, 11, 1303.

36 P. S. Alegaonkar, V. N. Bhoraskar, P. Balaya and P. S. Goyal, Appl. Phys. Lett., 2002, 80, 640. 